\title{
Raging Bull: A Story of Physical and Psychological Self-destruction in Boxing
}

\author{
Arturo Leyva ${ }^{1,2}$ \\ ${ }^{1}$ Department of Teaching and Learning, Florida International University, Miami, Florida, The United States \\ ${ }^{2}$ Department of Philosophy, University of Miami, Miami, Florida, The United States
}

Email address:

aleyva@fiu.edu

\section{To cite this article:}

Arturo Leyva. Raging Bull: A Story of Physical and Psychological Self-destruction in Boxing. American Journal of Sports Science. Vol. 8, No. 4, 2020, pp. 81-88. doi: 10.11648/j.ajss.20200804.11

Received: August 12, 2020; Accepted: October 5, 2020; Published: October 26, 2020

\begin{abstract}
This paper proposes a new reading of Martin Scorsese's 1980 film Raging Bull. It departs from established academic interpretations that focus on the main protagonist, the former middleweight champion, Jake LaMotta, and his toxic or overtly violent masculinity. Instead, while such interpretations touch upon important aspects of the film, the common claim by philosophy of film scholars that theirs is the only valid reading of Scorsese's work is dubious. Arguing against elitist interpretations that border on calls for prohibition of the film, this contribution presents a new approach to Raging Bull. It is informed by sociological and ethnographic accounts from the US-American boxing milieu in the 20th century. This approach makes it necessary to ground an interpretation of Raging Bull in the actual circumstances of boxing in the United States where two views on the urban gym in social hot spots have been established. Those views are as follows: (i) the gym is perceived as something like a safe space and frontier against the outside world with all its troubles, and (ii) the gym is perceived through the lens of the various ideologies and socio-economic problems that permeate it on a daily basis and control much of what goes on inside. This sympathetic interpretation is supported by LaMotta's autobiography, which served as a foundation for the film and supports the conclusion that there is a constant dialectical process between Jake's violent behavior and the moral codes he was taught to obey, particularly those relating to the traditional institution of the family, whose rules govern Jake, even in total isolation.
\end{abstract}

Keywords: Philosophy of Film, Sport and Culture, Raging Bull, Adaptations

\section{Introduction}

Martin Scorsese's film1980 film Raging Bull is considered to be his masterpiece [1]. Based on Paul Schrader's and Mardik Martin's adaptation of Jake LaMotta's autobiography Raging Bull: My Story, the film depicts the life and professional career of LaMotta as portrayed by Robert De Niro.

While most commentators have focused on interpreting Scorsese's Raging Bull from a psychological perspective or criticizing the depiction of Jake LaMotta's toxic and overtly violent masculinity, I propose a different reading. While the extant philosophy of film interpretations, which are grounded in psychology and gender studies, might touch upon important aspects of Raging Bull, those readings cannot claim to be the sole valid interpretation of Scorsese's work. Feminist commentators in particular have developed critiques of Raging Bull that sometimes go beyond common film analytical frameworks and media studies by expressing a level of disdain for the film that comes close to calling for its prohibition.

Irrespective of such propositions, what unites the existing approaches to Raging Bull is the tendency to intellectualize the film in such a way that the entire narration of LaMotta's professional career and personal life is interpreted through an elitist lens: the film about a boxer becomes universalized as a work with moral significance. On the one hand, such accounts elevate Raging Bull as an example of classic Hollywood cinema - a ranking it surely deserves. However, on the other hand, these interpretations stand in stark contrast to both the social milieu depicted within the film and the actual situation of boxing as a sport in society during the time of its production up through today.

Therefore, I propose a new interpretation of Scorsese's 
Raging Bull that is grounded in an examination of the social context in which boxing takes place. The goal is not only to analyze Robert De Niro's performance as LaMotta but also to understand it in a broader framework: This understanding can occur only if boxing and its depiction in the film are not analyzed as an abstract art form devoid of any social situatedness. Instead, the proposed interpretation suggests a problematization of existing psychological and feminist approaches. Therefore, a socially contextualized evaluation of Raging Bull does not claim to refute this film for its content but, rather, seeks a sympathetic understanding of its form. This approach considers the perspectives of sociological and ethnographic researchers among US-American professional and nonprofessional boxers as a basis for the film's analysis. It also compares LaMotta's original autobiography with Scorsese's adaptation.

First, I briefly examine early reviews of Martin Scorsese's Raging Bull and show how they form the basis for later interpretative approaches among scholars from various disciplines (Section 2). I also review how the analysis is grounded in a sociological overview of boxing (Section 3). The new interpretation in Section 4 is derived from that perspective and focuses on aspects of expressivity, articulation, and how LaMotta's attempts in these directions result in his eventual self-destruction.

\section{Raging Bull Through an Academic Lens: A Film in the Eyes of Others}

\subsection{Early Reception}

After its release in 1980, the first reviews of Martin Scorsese's Raging Bull had identified and established consensus around several key topics in the film. Some of the most influential texts are reprinted in Kevin J. Hayes' handbook, Martin Scorsese's Raging Bull (2005), which are cited in this article. It seems appropriate to describe these reviews by famous critics such as Jay Scott and Philip Wuntch as laying the conceptual foundation for many of the interpretative works by academic scholars that have followed since the late 1980s.

The idea to focus on these journalists' reviews despite their tendency toward bias derives from Umberto Eco's famous dictum to "work on a contemporary author as if he were ancient, and an ancient as if he were contemporary" [2]. In other words: to account for the relatively short tradition of Raging Bull's academic treatment, a review of the earliest documents is conducted to fill the lacunae of scholarly research. Nevertheless, the passage from early journalism to later academic interpretations never occurs without profound changes in the interpretations themselves: While many critics wrote about a certain aspect of nostalgia in Raging Bull, later academia did not continue this strand. It did, however, focus on the depiction of women - a topic entirely missing from the early reviews. Therefore, including early non-academic interpretations allows me to highlight critical facets that have previously gone unnoticed in the scholarly research.

Even by the time of its release, critics had agreed upon the significance of Scorsese's Raging Bull. For example, Newsweek's Jack Kroll praised the film, saying, "Raging Bull is the best American film of the year, Scorsese's best film..." [3]. Among the different aspects of the film on which these critics focused, two are noteworthy for the present paper. First, most authors highlight Scorsese's film technique: Eric Gerber explains that much of the anti-romantic atmosphere in Raging Bull stems from the director's decision "to film in black and white" [4]. According to Seitz [5], on the one hand, the monochrome imagery correspond to classic boxing films from the $1930 \mathrm{~s}$ to the 1950s that were shot before the advent of color films. The technique, therefore, encourages a retrospective reading that contains elements of nostalgia. The decision to use eight-millimeter film, which follows the optics of home films to narrate the transition through Jake LaMotta's career and his family life, as well as the introductory depiction of Jake in the ring that resembles early TV aesthetics, creates a setting that is supposed to transport the viewer back to the actual time of Jake's life. On the other hand, critics have asserted that the black and white film shot in original New York locations showed some of the grayness and grittiness in which the main protagonist grew up and lived. The film palpably communicates the socially cold areas of New York's more impoverished districts as being emotionally void through their colorless representation film.

Many critics associate this combination of nostalgia and coldness through black and white filming with Scorsese's overall style. Vern Stefanic and Joe Pollack describe Robert De Niro's Jake LaMotta as a "complex and grimly realistic" character [6], and the refer to the fight scenes as being "more realistic than in any other boxing film" [7]. Gerber explains that "it's too simple a description to label Raging Bull as realistic (or Realistic, for that matter)" because Scorsese approaches his material in an "expressionistic manner" [4]. Instead of Realism, Gerber sees a certain "19th-century naturalism with its unyielding pessimism and man-as-animal motif" at work [4].

Although Gerber observes that Raging Bull devotes "less than 15 minutes to in-the-ring boxing footage" [4], a typical response among early critics of Scorsese's film is how they were nearly physically overwhelmed by the film: "Raging Bull still leaves you feeling as though you had ducked and winced through a full two hours of on-screen punches," [4]; it "is both compelling and disturbing" [5] and "knocks you out and leaves you cold" [8].

This is primarily the overwhelming impression that the film left with its critics that created the conceptual basis for the following academic accounts: On the one hand, the critics' opinion is a response to the realistic or naturalistic depiction of the boxing scenes mentioned above. On the other hand, it becomes clear throughout the reviews that Scorsese's way of dealing with audiences' expectations of typical boxing films created a severe problem for the reception of Raging Bull: Scorsese takes the average boxing 
film with its elements of an adventure story and a victorious hero subjects it to the punches of an alcoholic adulterer protagonist who abuses his relatives. Critics read the film in terms of a "melodramatic format" [9] and highlighted the narrative linearity of the plot: The "astonishing" metamorphosis [9] of De Niro's character from a young, well-trained fighter to an overweight, alcoholic old man seems to have supported this processual reading of the film. Furthermore, both LaMotta's professional career and his personal life contribute to the continual development throughout the entire film: In contrast to classic boxing films, where family life provides an idyllic antidote to the grimness of gym training and prize fights, Scorsese abolishes this distinction. By maintaining a "neutral attitude toward the violence" [5], he inspires the question, "Where's the moral?" [9].

It is precisely Raging Bull's self-referentiality - its play with the genre - and the overwhelming screen aesthetics that left critics speechless. However, even the film's early reception shows that the engaging depiction of LaMotta's life and career raised several interpretative questions whose significance has continued in academic approaches to Scorsese's film.

\subsection{Academic Interpretations of Raging Bull}

Among the many boxing films produced in 20th-century Hollywood cinema, Martin Scorsese's Raging Bull has, by far, received the most attention. However, it is impossible to invoke established academic traditions to interpret this film. Although Raging Bull is one of Scorsese's most popular works, it has never received more than marginal scholarly attention. Thus, instead of reconstructing a coherent interpretation by analyzing the few passages in which scholars mention the film only in passing, this section focuses on the two most noteworthy approaches for the present context.

Serrano [10] views Raging Bull as a story of redemption. While several previous commentators have refuted the idea Jake LaMotta's life in the film is an unambiguous process of redemption or hope of redemption [11], Serrano echoes Scorsese's opinion, according to which the film "is really a straight, simple story, almost linear, of a guy attaining something and losing everything, and then redeeming himself. Spiritually" [12].

To prove his point, Serrano refers to the notion of redemption in the broader context of Catholicism, the genre of boxing films, and Martin Scorsese's overall work. His main argument is as follows:

Scorsese uses Raging Bull to criticize a ritualistic view of redemption by portraying the beginning of Jake's search as a futile attempt to submit himself to a public spectacle of ritual violence in the boxing ring while visually relating this view to (Catholic) sacraments and the crucification [10].

In Catholicism, the salvation of the soul is mostly considered endangered by the sinfulness of the flesh; thus, going through conflict causes an individual as a free agent to feel guilt for his or her past sinful actions. However, with Paul
Ricœur, Serrano explained that guilt is usually considered "a private emotion, unlike shame, which is a public one" [10]. As a result of Scorsese's ongoing interest in Catholicism, the confession of sins, and redemption, Serrano referred to Scorsese's cinema as a soteriology "in its own way" [10].

The mode through which to achieve such redemption, for Scorsese as well as for medieval Catholicism, is violence. Through violence in its conventional form and as a visual representation, Scorsese attempted to show the specific visual qualities of cinematic art and how LaMotta's life was marked by redemptive suffering. Serrano believes that Jake's notion of violence is best described by René Girard's distinction between generative and destructive violence: As Serrano [10] points out, destructive violence contributes to the vicious circle of endemic violence that threatens everyone whereas generative violence stops that vicious circle. For Serrano, Jake has a penitential opinion about the violence that allows him to see every publicly received punch as necessary to redeeming the sins committed in his personal life. Jake supposedly "ritualizes violence in the ring" [10] through a routine that confirms his view of redemption and establishes Jake's imaginary self-concept as a sacrificed agnus dei. In the "bloody spectacle" of his last fight against Sugar Ray Robinson, LaMotta transfigured the boxing ring "into the altar where the rite of his sacrifice will be performed" [10].

Beyond this interpretation, which draws upon Catholic elements in Martin Scorsese's work, many scholars have examined and sharply criticized the depiction of women in Raging Bull. For example, Peggy McCormack sees Jake LaMotta as "a deeply insecure, violently tempered, sexually paranoid, profoundly ambitious, extremely traditionalist male," who "reflects historical, cultural, social, economic, physical, and psychological gender ideologies" [13]. Women, in contrast, "end up reduced through narrative closure to similar fates: They are objectified, anatomized, and fetishized" [13].

For McCormack, women in Raging Bull do not function as independent subjects but always stand in relation to Jake, whose subjectivity establishes the center of the film's ensemble. Scorsese achieved this magnetic trend toward Jake as center and back from him to the female characters of the film through a number of techniques. Overall, the film presents these women's consciousness in one of three ways: as uninteresting to know; as unknown; or, worst of all, in Vickie's case, unknowable and therefore an object of obsessive, frustrated, violently jealous scrutiny on Jake's part [13].

It would, of course, be possible to explain this ego-centered perspective of Scorsese's film by dismissing it as the result of various cinematic demands for a main protagonist. However, this argument is shortsighted because it overlooks the genre history of boxing films. In this context, Scorsese's work departs from earlier cinematic techniques that necessarily focused on the boxer as a hero by presenting a somewhat more complicated view of LaMotta: He is still the center of attention; however, he has lost his status as hero. In other words, with Raging Bull, the genre enters the stage of postheroism. It even presents 
LaMotta as an anti-hero rather than the audience's relatable darling.

While Jake's first wife, Irma, appears to be a "shrike" [13] who regularly fights with her husband, Scorsese depicts Vickie as a multidimensional enigmatic being who is fetishized by Jake and whose sexuality he desires to control. The film depicts their relationship through three different filmic modes, not merely in terms of stylistic approach but literally in the type of film stock used to shoot specific scenes. For example, the so-called objective narration and what McCormack calls "Jake's moments of perceptual subjectivity, surveilling Vickie" [13] are shot like color family films on eight-millimeter film. While the home films show something like the dream world of a successful relationship, the objective narration unveils the brutal reality behind it. However, the two worlds are connected through slow-motion sequences that reveal Jake's uncertainty and fear of not being able to control Vickie sexually.

In contrast to the many facets of Vickie and the dull but nevertheless relatable depiction of Irma, the nightclub women at the end of the film appear as anonymous and, what is even worse, they appear as objects or commodities, "rentable in sexual and economic exchange terms" [13]. Although these women come much closer to Jake's first wife, Irma, than to Vickie, they are still behind Irma as she had been part of the family for some time. Jake does not display any interest in the nightclub women.

To summarize McCormack's approaches to Raging Bull as an example of a gender studies perspective, it is clear that the author does not merely offer an interpretation of Scorsese's film but actively criticizes it for its ideologies. In McCormack's eyes, the way in which Scorsese "employs both narrative structure and editing pace" increases "the movies's bond between Jake and us" [13], thus hampering any attempts by viewers to establish critical distance between themselves and De Niro as LaMotta. Jake's domestic fights with and abuse of his two wives and, later on, other family members also appear to find their completion in LaMotta's ability to withstand any number of punches in the ring. For McCormack, "Jake is subconsciously driven to take abuse in the ring as compensation for the abuse he dispenses at home" [13].

A number of authors have also argued that the continuing repression of LaMotta in Raging Bull is of a sexual nature. The general idea is that LaMotta is a repressed homosexual who uses boxing as a way of transforming sexual repression into violence $[14,15]$. Masculinity, violence and repression continue to be points of contention: I agree with Grist's [16] idea that the implications of LaMotta's masochistic features of Jake's representation need to be explored. While Grist [16] approaches the subject psychoanalytically, I believe that LaMotta's character must be analyzed within the sociological context of boxing and in terms of what exactly its implications might be for the protagonist. The effects of this sociological context on LaMotta have remained, to my knowledge, largely uncharted.

\section{3. 'Our Last Hope Was Boxing': The Sociology of a Sport and the Dream of a Better Future}

Thus, in contrast to existing academic interpretations of Martin Scorsese's Raging Bull as a story about redemption or a tale of despicable masculinity, I propose a view that derives from the sociological context of boxing. To develop such an approach seems appropriate given the amount of time the real LaMotta [17] spends in his autobiography narrating his origins in the slums of the Bronx and his upbringing during the Great Depression. According to LaMotta [17], his fighting style mostly developed on the streets of New York in fights with other children and teens long before he became a professional.

From an adaptation studies perspective, several passages in Jake LaMotta's autobiography, a book he wrote together with Joseph Carter and Peter Savage, is full of references to LaMotta's life and social milieu, which the author sees as having determined his entire career. Furthermore, at several points throughout LaMotta's autobiography, the boxer describes his memories appearing to him as if they were in "an old black-and-white movie" [17].

In addition to a growing corpus of ethnographic literature on the sociology of boxing [18-20], more nuanced perspectives on boxers and fighters have also reached popular culture. Many films, books, and even video games depict protagonists who are not merely male brutes but psychologically complex characters that require thorough interpretations. A case in point is Gospodinov's [21] internationally acclaimed novel, The Physics of Sorrow. One of the main protagonists is the famous Minotaur of Ancient Greek mythology. In contrast to his usual reception as a dangerous monster living in a maze on the island of Crete that annually devours seven youths and seven maidens, Gospodinov depicts the Minotaur as a tragic protagonist who is isolated from the world: "The Minotaur is not guilty. He is a boy locked up in a basement. He is frightened. They have abandoned him" [21].

An example that comes even closer to a more nuanced cultural depiction of boxers is the novel The Boxer by the Polish-German writer Becker [22]. Becker, the child of a Jewish family that lived in the former German regions of today's Poland, who survived the Second World War, published his novel in the former East German Democratic Republic. The story is about a Jewish man called Aron Blank who survived the Holocaust and lives in East Berlin, making use of all amenities the - officially anti-fascist - East German state offers him as a former Nazi persecutee. However, he continues to mistrust his fellow German citizens and decides to turn his own son, Mark, into a strong and independent boxer. After his son emigrates to Israel, he presumably dies in the Six-Day War and leaves his father behind in Berlin, who, as a lonely and cynical old man, tells his story to a young interviewer.

Gospodinov's Minotaur and Becker's boxer are just 
literary examples of a tendency toward a more complex and sophisticated picture of fighters in general. Nevertheless, sociological and ethnographic researchers have similarly begun to examine boxing in ways that discuss its one-sided reception in society and popular culture. By now, academic discourses such as carnal ethnography have become key issues of contemporary sociology, participating in more general trends such as embodiment studies [23].

A seminal study regarding the sociology of boxing is Bourdieu's and Wacquant's [24] cooperation on $A n$ Invitation to Reflexive Sociology. It is partially the result of Wacquant's ongoing ethnography of boxing in a Chicago gym around 1990. In one of his papers, Wacquant notes a striking discrepancy between the intellectual fascination with boxing, on the one hand, and the scathing criticism it often triggers on the other [19]. When he began this work, boxing was considered a topic not worthy of sociological study and overblown by journalistic accounts of famous champions. A noteworthy example is how the media depicted boxers such Mike Tyson during that time:

Boxers are rugged, near-illiterate young men who, raised in broken homes under conditions of deprivation, manage single-handedly to elevate themselves from the gutter to fame and fortune, parlaying their anger at the world and sadomasochistic craving for violence into million-dollar careers, save for those who, ruthlessly exploited by callous managers and promoters alike, end up on the dole with broken bones and hearts [19].

Wacquant proposes the pursuit of ethnographic studies of local gyms in social hot spots as an antidote to such popular accounts of boxing as a despicable, yet strangely fascinating sport. Following Bourdieu's theory of habitus, and employing participatory observation as the main tool of his research, Wacquant came to the conclusion that the gym offered an alternate world to street violence and problems in social life: The gym serves as "an island of order." Wacquant argues that "the boxing gym defines itself in a relation of symbiotic opposition to the ghetto in which it is situated, and from which it both draws its sustenance and protects its members" [19].

Although Wacquant's notion of boxing as a "social art" might be initially convincing, it has drawn considerable criticism. Trimbur's [20] ethnographic study of a Brooklyn boxing gym is in some way a replication of Wacquant's original work. However, neither the source material nor Trimbur's interpretation of it confirm Wacquant's findings. For Trimbur, the boxing gym is not a safe space from the outside world but, rather, a place that is profoundly penetrated by social and ideological problems.

The basic pattern of relationships between trainers and (amateur) boxers in this Brooklyn gym is "tough love": The trope signifies the trainers' attempts to push their wards to new limits, that is, to mold them. However, the trainers do not savor situations of physical suffering per se but, rather, use them as wake-up calls for the troubled amateur boxers. This trope often happens through appeals to masculine stereotypes such as will, assertiveness, power of endurance, and determination: "Tough love is the most often articulated trope of training practices. The trope bespeaks the care, devotion, and responsibility that trainers have for their amateurs while acknowledging the particular demands and realities of pugilism" [20].

While the trainers are open to hearing the various problems of their boxers, they simultaneously draw from neoliberal ideologies of individualism to provide possible solutions. The boxers are inclined to change their behavior in ways that allow them to cope with the outside world. However, the trainers' discourses are inherently contradictory since they also criticize injustice, racism, and socio-economic power relations: "In the urban gym, these divergent discourses are reconciled and work together to help men of color address, at a micro, everyday level, the situations of a racialized postindustrial landscape" [20].

To summarize this review of the sociological literature on boxing, it seems appropriate to argue that, two views currently dominate the field: On the one hand, Wacquant offers the notion of the gym as an idyllic island inside a world of trouble. On the other hand, ethnographers such as Trimbur aim to show that the problems of the outside world profoundly permeate the gym and boxing as a whole, structuring relationships among gym members and their discourse. Needless to say that it is not compulsory to decide between one of those views; rather, it is safe to assume that these experiences might also differ across various gyms in American cities. Nevertheless, it becomes clear that boxing is neither simply the fascinating public spectacle of journalists and prize fights nor a subproletarian valve for uneducated men. To fully grasp the social logic of boxing, it is necessary to understand it as a sport where physical strength meets psychological insecurities. Mind and body, however, cannot be separated and are equally permeated by the social, economic, and cultural contexts in which they exist.

\section{Silenced Subjects, Talking Actions, Shattered Bodies: A New Interpretation of Raging Bull}

Although I propose a new interpretation of Martin Scorsese's Raging Bull that is derived from a sociological contextualization of boxing in US-American culture, my analysis of the film aims at more than mere comparisons between Jake LaMotta's life and the actual situation for boxers in the 1930s, 1940s, and 1950s, the time of LaMotta's career, the 1980s, when Scorsese shot his film, or today. I do not conceptualize Raging Bull as a film about (self-) redemption, as a critique or performance of gender ideologies: I seek to show that Raging Bull is about physical and psychological self-destruction. I do so by analyzing the film's technique, through neither a formalist close reading nor a mere sociological study of context. Instead, I argue for a reasonably contextualized analysis of how Scorsese engages with the social context of boxing and 
how LaMotta's development is not a redemptive victory of soul over flesh; rather, it is driven by persistent, self-destructive physical and psychological behavior.

This becomes evident through two interpretative perspectives. The analysis is grounded in the aforementioned context of sociological and ethnographic studies on boxing. It is, however, an analysis that combines such approaches with an interpretation of how the film depicts LaMotta's inner, psychological life. Thus, the proposed reading follows Nich Tosches's observation in his 1997 introduction to LaMotta's autobiography:

La Motta's autobiographical accounts of his battles with Robinson, and of other fights, are terrific. However, Raging Bull is far more than a book of fight stories, just as it is far more than the usual gritty-reality hokum. As Jake's endurance in the ring was a rare human achievement, so is his book Raging Bull as it provides a glimpse into the soul lurking beneath a blinding storm of - yes, the title is perfect - rage, a rage born of furious fear and willfulness [25].

First, what is most surprising about the depiction of LaMotta's career in Scorsese's film is probably the lack of training and nearly total absence of a trainer. Of course there is a trainer, Mario, and there is also a scene where Jake trains for his next fight. However, it could be argued that the film does not focus on Jake's preparations for his fights and the ongoing training since, from the very beginning, he is already a professional boxer who does not train in the same way an amateur would. However, even the rare instances where the viewer does see Jake train are a departure from regular boxing practices.

Here, too, it can be argued that the lack of training scenes follows cinematic demands based on the length of the film. However, the relative lack of training in Scorsese's film appears to be correlated in relation to the film's full length. Theoretically, Scorsese could have presented his audience with another cut in the postediting process that focused more on LaMotta's training sessions. There is, however, a very simple reason why the director decided against it: By cutting out vast parts of an actual professional boxer's daily routine, Scorsese directed De Niro's portrayal of LaMotta to appear as more primeval or carnal. In Scorsese's adaptation - as well as in LaMotta's autobiography [25] - LaMotta is driven by his desire to hurt and get hurt: boxing is in his blood, and a trainer would be nothing more than a rational voice that obscures the sheer brutality of the boxer's approach to his sport.

Jake's only appearance at his local gym happens right at the beginning of Raging Bull (0:15:04-0:17:13). He is sparring with his brother Joey, wearing notably more protective gear than Jake. As Joey is always on the defensive, moving away from his brother, it becomes evident that he is little more than a living punching bag to Jake: He lacks technical skill, and any attempt to land a punch on Jake fails. After Salvy and his gang enter the gym to watch Jake, he gets angry at Joey and provokes him. However, he leaves Joey no chance to attack him as he channels his anger in a tirade of hard punches against his brother who can barely keep up and hits the ground, where he stays until the bell rings. When the training continues, Joey tries to throw some punches, which are so weak that they make Jake laugh.

Something similar occurs before Jake's match against the middleweight champion Marcel Cerdan (1:13:35-1:18:20). In the dressing room, Joey wears the same protective gear and leans against the wall while Jake throws some punches at him before he leaves for the fight. Before moving on to my interpretation of the apparent lack of training in the film, I also want to highlight the absence of a trainer. There is, of course, Jake's trainer Mario whose first appearance is also in the gym scene. However, except for minor appearances during fights, there are only two more scenes in which Mario makes a lasting impression.

After the fight against Janiro, Mario enters the steam bath where Jake is warming up (0:58:22-0:59:02). Mario does not allow Jake to drink so that he can lose four more pounds and tells him that he must continue his training and keep moving. Mario's other appearance occurs right after Jake's fight against Fox, which he intentionally loses to close the deal with the mob and their bookies by quitting after the fourth round (1:11:28-1:12:22). A clearly shaken LaMotta cries in the arms of Mario and tells him that he cannot continue any longer. Mario tells him to quit boxing altogether because "this is a free country." Jake regrets his decision to accept the mafia's deal and repeatedly asks: "What have I done?" Jake's existential question causes even Mario to start crying before he has to fight off reporters trying to enter the dressing room.

Thus, what is one to make of this apparent lack of both training and a trainer in Scorsese's Raging Bull? Is this a mere coincidence - or does the absence of these elements that seem so important to sociologists and ethnographers of contemporary US-American boxing culture convey a more profound message?

First, Mario is probably the most clear-cut protagonist of Scorsese's film, and he appears only as a projection of Jake's mind. He does indeed appear to be a protagonist; however, his entire figure is covered in an enigmatic veil. His appearance in the steam bath highlights his unworldly character: When he enters the bath, he is little more than a shape amid steam, with what can be read as epiphanic light surrounding his head. In this scene, Mario fulfills the function of Jake's inner voice that tells him he must lose more weight if he wants his career path to continue. His remarks confirm this somewhat moralizing role of Mario after Jake accepts the deal with Tommy by losing against Fox: Mario appeals to Jake's moral sense and proposes that it would be better for him to quit boxing altogether than to defile the sport with his connections to the mob. It is no coincidence that this is the last important appearance of the trainer figure in Raging Bull: Jake's emotional state brings even Mario to tears as he realizes that there is no way out for his protégé. This is precisely the moment at which any hope for morality ends: While Jake's violent behavior against his peers and family is somewhat in accordance with the environment in which he lives, he also nurtures the sense that 
boxing is a necessity. He must move on, he cannot stop, and any inner moral voice (externally embodied by Mario) is silenced. Jake's wholesale acceptance of violence, morality, and socially accepted norms makes his fateful end inevitable - he is thrown in jail.

Second, the lack of images of the gym heightens the impression of social isolation. While researchers argue that the gym community - trainers, amateurs, and professionals tend to form a secure connection that also permeates the outside world, Jake does not have any such relationships. When he goes to the gym, he trains with his brother Joey and sees the visitors around Salvy as intruders. Jake has no contact with other boxers except for the punches he throws at them during fights. In fact, during the entire film, there are only two instances where Jake touches another boxer in other ways: He hugs Cerdan after winning the championship in what appears to be a grand gesture of thankfulness. Then, during his final fight with Sugar Ray Robinson, he first shouts at him to provoke more punches; after the match, a brutally beaten Jake tells Robinson, "You never gotten me down, Ray!"

What is left of Jake's relationships? The answer is presented precisely in the first shot of the film: To the music of Mascagni's Cavalleria rusticana, Jake stands alone in the ring, wearing his coat. Scorsese employs an aesthetic that simultaneously turns the viewer into a voyeur in the bloody early TV spectacle of Jake's life and career and that establishes a future so vividly materialized that the ropes look like prison bars. However, this future works both ways: Jake is separated from the world outside of the ring, too. He is isolated, and the film shows how his violent path of psychological and physical self-destruction continually cuts off any tether to the outside world.

It is precisely this isolation that is ever more apparent and of growing importance throughout the film as it manifests itself in Jake's unorthodox behavior against his own family. In many ways, Jake's rage against his brother in the gym and before the fight against Cerdan is the result of the fights they had growing up. However, these fights are, in both instances, the result of Joey stepping in to hold Jake back in his violent behavior against others. While Jake channels his initial anger at Joey, who is still protected by his gear, Jake's feeling of guilt is immediately transformed into his willingness to receive blowing punches by his various opponents in the ring. The more serious his offense, the more punches he takes before striking down his opponent.

The film arrives at the climax of this development, of course, after Jake brutally beats up Joey because he suspects him of cheating on him with his wife $(1: 30: 48-1: 31: 50)$. This time, channeling his anger is not possible because Jake's violent feelings after learning about this rumor from his wife Vicky in a heated discussion are immediately transferred onto Joey in his home. This event leads to an increased willingness to take punches: first by Dauthuille, then, after an attempt to reconcile with his brother, by Sugar Ray Robinson in their final fight. The connection between Jake and Joey is lost, and even a few years later, when an older
Jake meets his brother on the street, there is no coming back.

The story of Jake's self-destruction is expressed through his relationship with his family. However, this growing estrangement is not only shocking; from its beginning, the film points toward LaMotta's decline because his first fight against Reeves is also the first fight Jake ever loses. Furthermore, Jake's relationship with his family somewhat contradicts his loss of a moral compass as expressed by the film's silencing of the trainer's voice. In other words, would Jake truly have had such feelings of guilt about his behavior if he had truly lost his morality?

Jake's willingness to take punches, a kind of auto-aggressive behavior facilitated by the sport that he continually pursues, grows over time not because Jake loses the human ability to follow moral codes but because he still follows them. For Jake, the remaining vestige of his social and professional life is tied up with his relationship with his family and with his brother in particular: The implicit rule of the family, this essential element of traditional Italian-American immigrant culture, is present throughout the entire film. It is precisely this persisting association, and Jake's rebellion against it, his way of violently playing with its rules, that makes his path of self-destruction even more shocking. It is, therefore, no coincidence that Jake meets his brother one more time on the street after his self-destructive catharsis in the prison cell: Jake re-enters the moral codex he sought to destroy and submits to its power.

However, Jake's re-integration is one-sided: Although he is now able to continue his life according to the traditional rules, his family has cut off all ties with him. According to filmic logic, Jake is not entirely isolated. No one is watching him except himself in the mirror and the viewer in the cinema. However, even the viewer fades out at the end of the film: In his dressing room, Jake repeats his old preparation of punching someone (2:01:03-2:03:54). However, now he can only shadow-box, and he leaves the screen so that he is not even visible in the mirror: In the end, no one is watching.

\section{Conclusion}

This paper proposed an approach to a new interpretation of Martin Scorsese's classic 1980 film Raging Bull. This approach critically engaged with the existing interpretations of the film that often speak of its redemptive potential or refute its gender-biased ideologies. I attempt to show that many of these arguments actually derive from the earliest reviews of Raging Bull after its initial release in 1980.

At that time, critics have wondered about this boxing film, which barely shows any boxing, the overtly brutal depiction of LaMotta's violence against other boxers and his own family and the exciting use of camera techniques. Many authors frame Scorsese's film from a realistic or traditional perspective that highlights the socially cold and gray way of life in the Bronx from the 1930s into the 1950s. While classic boxing films often leave out the private lives of their protagonists or present the gym as an idyllic haven for men engaging in this violent sport, Raging Bull departs from this 
genre tradition. Instead, it fuses life and career into an interdependent unity in which its anti-protagonist's violence against his family is perpetuated by his willingness to receive punches from his opponents in the ring and vice-versa. The film's tendency to depict a story of decline has led some commentators to think of Raging Bull as a story of redemption, especially in the context of Catholicism, which played an essential role for Italian Americans around the 1940s. Similarly, Catholicism is significant to both Scorsese and Robert De Niro; thus, Jake LaMotta's life and career might be understood in terms of a continuing attempt to find redemption for the severe sins he committed.

However, consideration of the social science and ethnographic research reveals that it is necessary to ground an interpretation of Raging Bull in the actual circumstances of boxing in the United States. Since the early 1990s, two views have been established on the role of the urban gym in social hot spots: According to the first, the gym appears as something like a safe space and frontier against the outside world with all its troubles; according to the other, various ideologies and socio-economic problems permeate the gym on a daily basis and control much of occurs inside.

Taking a sociologically informed approach, it is possible to ground Jake LaMotta's story in Raging Bull as a narrative of physical and psychological self-destruction. The presented analysis and interpretation of the film focus on the apparent lack of training and the absence of a trainer figure for Jake. As a result, Scorsese's shocks become understandable as the result of a constant dialectical process between Jake's violent behavior and the moral codes he was raised to obey. The central feature of this condition, however, is the traditional institution of family, whose rules govern Jake, even in total isolation.

\section{References}

[1] Baker, A. (2014) A Companion to Martin Scorsese. Hoboken, NJ: Wiley.

[2] Eco, U. (2015) How to Write a Thesis. Cambridge and London: The MIT Press.

[3] Rausch, A. J. (2010) The Films of Martin Scorsese and Robert De Niro. Maryland: Scarecrow Press.

[4] Gerber (2005) Raging Bull. Houston Post. 19 December 1980, p. 1E, reprinted in Hayes, K. (2005) Martin Scorsese's Raging Bull. Cambridge: Cambridge University Press. pp. 137-139.

[5] Seitz, M. (2005) From 'Musclemen'. The Progressive. February 1981, pp. 50-51, reprinted in Hayes, K. (2005) Martin Scorsese's Raging Bull. Cambridge: Cambridge University Press. pp. 139-141.

[6] Stefanic, V. (2005) Raging Bull is a Gritty, Brutal Masterpiece. Tulsa World. 20 February 1981, p. C7, reprinted in Hayes, K. (2005) Martin Scorsese's Raging Bull. Cambridge: Cambridge University Press. pp. 145-147.

[7] Pollack, J. (2005) Raging Bull. St. Louis Post-Dispatch. 20 February 1981, p. 5D, reprinted in Hayes, K. (2005) Martin
Scorsese's Raging Bull. Cambridge: Cambridge University Press. pp. 143-145.

[8] Wuntch, P. (2005) De Niro Packs a Mean Punch: Stunning but Unsentimental, Raging Bull Scores a KO. The Dallas Morning News. 19 December 1980, p. 1C, reprinted in Hayes, K. (2005) Martin Scorsese's Raging Bull. Cambridge: Cambridge University Press. pp. 142-143.

[9] Scott, J. (2005) Raging Bull: No Punches Pulled. The Globe and Mail. 15 November 1980, p. 3, reprinted in Hayes, K. (2005) Martin Scorsese's Raging Bull. Cambridge: Cambridge University Press. pp. 135-137.

[10] Serrano, A. (2015) The spectacle of redemption: guilt and violence in Martin Scorsese's Raging Bull. Studia Gilsomiana, 4: 131-148.

[11] Wilson, M. H. (1999) "Raging Bull" in Brunette, P. Martin Scorsese: Interviews. University Press of Mississippi. pp. 88-89.

[12] Kelly, M. P. (1980) Martin Scorsese, the First Decade. Redgrave Publishing Company. pp. 32.

[13] McCormack, P. (2005) "Women in Raging Bull: Scorsese's use of determinist, objective, and subjective techniques," in Martin Scorsese's Raging Bull, Hayes, K. Ed. Cambridge: Cambridge University Press, pp. 92-115.

[14] Cook, P. (1982) Masculinity in crisis. Screen, 23: 39-46.

[15] Wood, R. (1986). Raging Bull: the homosexual subtext. Movie, $31,108-14$.

[16] Grist, L. (2007) Masculinity, violence, resistance: a new psychoanalytic reading of Raging Bull. Atlantis, 29: 11-27.

[17] LaMotta, J. (1997) Raging Bull: My Story. Boston: Da Capo Press.

[18] Hoffman, S. G. and G. A. Fine (2005) The scholar's body: mixing it up with Loïc Wacquant. Qualitative Sociology, 28: 151-157.

[19] Wacquant, L. J. D. (1992) The social logic of boxing in Black Chicago: toward a sociology of pugilism. Sociology of Sport Journal, 9: 221-254.

[20] Trimbur, L. (2011) 'Tough love': mediation and articulation in the urban boxing gym. Ethnography, 12: 334-355.

[21] Gospodinov, G. (2015) The Physics of Sorrow. Rochester: Open Letter.

[22] Becker, J. (1976) Der Boxer. Rostock: Hinstorff Verlag.

[23] García, R. and D. Spencer (2013) "Introduction: carnal ethnography as path to embodied knowledge," in Fighting Scholars: Habitus and Ethnographies of Martial Arts and Combat Sports, García, R. and D. Spencer, Eds. London, New York and Delhi: Anthem Press, pp. 1-18.

[24] Bourdieu, P. and L. Wacquant (1992) An Invitation to Reflexive Sociology. Chicago: University of Chicago Press.

[25] Tosches, N. (1997) "Introduction," in Raging Bull: My Story, LaMotta, J., Ed. Boston: Da Capo Press, pp. vii-xii. 